\title{
Composição regional e centesimal da carcaça de cordeiros criados nos sistemas de produção orgânico e convencional ${ }^{1}$
}

\author{
Nivea Maria Brancacci Lopes Zeola², Américo Garcia da Silva Sobrinho², Gabriela Milani Manzi² \\ 1 Projeto financiado pela FAPESP. \\ 2 Universidade Estadual Paulista Júlio de Mesquita Filho, Faculdade de Ciências Agrárias e Veterinárias, Departamento de Zootecnia.
}

RESUMO - Este trabalho foi realizado para avaliar o rendimento dos cortes de carcaça, a área de olho-de-lombo, a composição centesimal e o perfil de ácidos graxos da carne proveniente de cordeiros submetidos aos sistemas de produção orgânico e convencional. Foram utilizados 48 animais Ile de France, com peso corporal médio de 15 kg, distribuídos em dois sistemas de produção, orgânica e convencional e abatidos aos $32 \mathrm{~kg}$ de peso corporal. Os sistemas de produção não influenciaram o peso nem o rendimento dos cortes de carcaça, entretanto o comprimento máximo do músculo longissimus dorsi dos cordeiros criados no sistema orgânico foi superior ao dos animais do sistema convencional, assim como a espessura máxima de gordura de cobertura. A profundidade máxima do músculo, a espessura mínima de gordura de cobertura e a área de olho-de-lombo não diferiram entre os tratamentos. Na composição centesimal do músculo longissimus dorsi, apenas a matéria mineral foi influenciada, pois foi menor nos animais do sistema orgânico em relação ao convencional. Para os parâmetros umidade, proteína bruta e gordura, não houve influência dos sistemas de produção. O perfil de ácidos graxos saturados e monoinsaturados não foi influenciado pelos sistemas de produção, entretanto o ácido graxo poliinsaturado C18:2 (linoleico) foi maior na carne dos cordeiros criados no sistema orgânico em comparação aos do sistema convencional. O peso e a porcentagem dos cortes da carcaça são semelhantes entre os cordeiros submetidos aos sistemas de produção orgânico e convencional. A carne daqueles criados no sistema orgânico apresenta maior largura máxima no músculo longissimus dorsi (medida A) e porcentagem do ácido graxo poliinsaturado linoleico e menor teor de matéria mineral.

Palavras-chave: ácidos graxos, área de olho-de-lombo, carne ovina, cortes da carcaça, longissimus dorsi, sustentabilidade

\section{Regional and centesimal composition of carcass of lambs raised under conventional and organic production models}

\begin{abstract}
This study was carried out to evaluate yield of carcass cuts, loin eye area, centesimal composition and fatty acids profile of carcass of meat from lambs raised under organic and conventional systems. Forty-eight Ile de France lambs, with average initial weight of $15 \mathrm{~kg}$ were distributed in two production models, organic and conventional, and slaughtered when final body weight reached $32 \mathrm{~kg}$. The production models did not affect weight or yields of carcass cuts; however, the longissimus dorsi muscle of lambs raised in the organic model was longer, compared with conventional system, as well as the maximum thickness of subcutaneous fat. Muscle maximum depth, minimum thickness of subcutaneous fat and eye loin area did not differ between treatments. In the longissimus dorsi muscle centesimal composition, only mineral matter was influenced; it was smaller in the organic model in relation to the conventional model. Moisture, crude protein and fat were not influenced by the treatments. Saturated and monounsaturated fatty acids were not influenced by the treatments; however linoleic acid was higher in meat of lambs submitted to organic the model. Weight and carcass cuts percentage are similar for the lambs submitted to the organic and conventional production models. The meat from those submitted to the organic model presents greater maximum width in the longissimus dorsi muscle (measurement A) and linoleic acid percentage and lower level of mineral matter.
\end{abstract}

Key Words: carcass cuts, fatty acid, loin eye area, longissimus dorsi, sheep meat, sustainability 


\section{Introdução}

O consumo de carne ovina no Brasil ainda é baixo, em torno de 800 g/per capita/ano, no entanto, o setor está em fase de crescimento, pois a produção atingirá, provavelmente, 100 milhões de cabeças nos próximos 10 anos e o segmento se firmará como boa alternativa de aplicação. Atualmente, a criação de cordeiros no País movimenta R 360 milhões ao ano, considerando o preço de venda do quilo da carne a R \$ 5,00 (Galvão, 2004).

A preferência pela carne ovina apresenta aspectos comuns, como a busca por carne macia com pouca gordura e muito músculo, comercializada a preços acessíveis (Silva Sobrinho, 2001). Assim, é fundamental nesta fase de crescimento da atividade a implantação de técnicas, durante a criação, o abate e o pós-abate, que otimizem o sistema de produção com nutrição adequada, manejo sanitário, bem-estar animal, assim como a caracterização dos parâmetros quantitativos da carcaça.

O consumo de alimentos orgânicos nos países desenvolvidos e em desenvolvimento tem crescido. No Brasil, esse crescimento é de $10 \%$ ao ano e, dada sua extensão territorial e diversidade de pastagens, tem potencial para se tornar o maior produtor e exportador de carne orgânica do mundo. Atualmente, a produção orgânica é ainda pequena em relação à convencional e o Brasil é o 34ํㅡ trigésimo quarto país na exportação de produtos orgânicos (Bellaver, 2002; Santos \& Monteiro, 2004).

A produção orgânica de alimentos mundial distribui-se em 46,3\% na Oceania, 22,6\% na Europa, 20,8\% na América Latina, 6,7\% na América do Norte, 2,6\% na Ásia e 1,0\% na África (Nardone et al., 2004; Paixão, 2005). O consumidor moderno busca consumir carne obtida humanitariamente, sendo importante garantir o bem-estar dos animais para que não sofram dor, injúria e estresse durante a criação e o abate. O abate humanitário consta no anexo da Instrução Normativa do Ministério da Agricultura, Pecuária e Abastecimento (MAPA), que apresenta o conjunto de diretrizes técnicas e científicas que garantem o bem-estar dos animais desde a recepção até a sangria (Barbosa Filho \& Silva, 2004).

O sistema convencional de produção agropecuária utilizando insumos químicos e processos de produção adversos tem sido muito questionado, pois a maioria dos sistemas ainda banaliza o bem-estar animal e os consumidores desejam comprar carne proveniente de sistemas que promoveram o bem-estar animal, ou seja, sustentável e ambientalmente corretos (Warriss, 2000; Araújo Filho, 2002; D’Almeida, 2005).

Este trabalho foi realizado para avaliar o rendimento dos cortes da carcaça, a área de olho-de-lombo, a composição centesimal e o perfil de ácidos graxos da carne proveniente de cordeiros produzidos nos sistemas de produção orgânica e convencional.

\section{Material e Métodos}

O experimento foi realizado na Faculdade de Ciências Agrárias e Veterinárias - FCAV, Unesp, Jaboticabal, São Paulo. A fase experimental foi desenvolvida nas dependências do Setor de Ovinocultura, pertencente ao Departamento de Zootecnia, e a fase laboratorial nos Laboratórios de Nutrição Animal e de Ruminantes, pertencentes ao Departamento de Zootecnia da FCAV. Para as análises da composição bromatológica dos ingredientes da ração, foram utilizadas as normas analíticas do Instituto Adolfo Lutz (2008).

Foram utilizados 48 cordeiros Ile de France, machos não-castrados, desde o nascimento até o abate, aos $32 \mathrm{~kg}$ de peso corporal, distribuídos em dois sistemas de produção, orgânica e convencional, com 24 cordeiros em cada sistema (tratamento). Os cordeiros foram identificados individualmente com brincos na orelha. A pesagem e o monitoramento das infecções parasitárias, pelo método FAMACHA (Molento et al., 2004) e pela contagem do número de ovos de nematódeos por grama de fezes (OPG), utilizando o método de McMaster modificado, descrito por Sloss et al. (1999), foram realizados a cada 14 dias. A desverminação foi recomendada toda vez que a contagem estivesse acima de 500 OPG, sendo que no sistema convencional foi utilizado anti-helmíntico sintético, tendo como princípio ativo a ivermectina, e no sistema orgânico o medicamento homeopático Arsenicum album na potência 30CH, fornecido 3 vezes por semana na água dos animais, na proporção de $0,3 \%$, pois os bebedouros nos piquetes tinham registro individual para abertura ou fechamento do fluxo de água, permitindo o controle do fornecimento. No concentrado dos animais do sistema orgânico, foi utilizado ainda fitoterápico comercial constituído por alho (Allium sativum L.) e neem (Azadirachta indica) na proporção de $2 \%$ do concentrado.

Este trabalho foi desenvolvido a partir do $60^{\circ}$ dia de gestação das ovelhas até o abate dos cordeiros, compreendendo um período médio de 238 dias, correspondente aos 88 últimos dias de gestação, aos 60 dias da fase do nascimento ao desmame e aos 90 dias da fase do desmame ao abate. A partir do último terço da gestação, as ovelhas foram colocadas na pastagem de capim-tifton 85 (Cynodon dactylon), permanecendo em áreas distintas conforme o sistema de produção, orgânico ou convencional.

As ovelhas receberam, do terço final da gestação até o desmame dos cordeiros, dieta formulada com $13,7 \%$ de 
proteína bruta (NRC, 2006), contendo 60\% de cana-deaçúcar e $40 \%$ de concentrado, constituído por $44,1 \%$ de milho moído, $55,0 \%$ de farelo de soja, $0,25 \%$ de fosfato bicálcico e $0,65 \%$ de sal mineral (Tabela 1 ).

Os cordeiros foram aleitados pelas ovelhas até o desmame, aos $15 \mathrm{~kg}$ de peso corporal, e tiveram livre acesso ao creep feeding, recebendo suplementação alimentar formulada com 20,0\% de proteína bruta (NRC, 2006), contendo 60,0\% de milho moído, 25,0\% de farelo de soja, $11,5 \%$ de farelo de trigo, 3,0\% de fosfato bicálcico e $0,5 \%$ de sal mineral (Tabela 2).

$\mathrm{O}$ acesso dos cordeiros ao concentrado foi livre, com fornecimento médio diário de 200 g/cordeiro, com pesagens diárias das quantidades fornecidas e das sobras, para cálculo do consumo médio diário dos cordeiros.

Quando os cordeiros foram desmamados, já distribuídos em dois grupos (sistema orgânico e convencional) de 24 animais, permaneceram na pastagem de capim-tifton 85 (Cynodon dactylon) e receberam dieta formulada com 18,0\% de proteína bruta (NRC, 2006), contendo 50\% de cana-de-açúcar e $50 \%$ de concentrado, constituído por 36,0\% de milho moído, $61,0 \%$ de farelo de soja, 2,6\% de fosfato bicálcico e 0,4\% de sal mineral (Tabela 3).

Foi utilizado 1,6 ha de pastagem, com duas áreas de 0,8 ha cada, utilizando-se pastejo rotacionado, com período de ocupação de 7 dias e descanso de 45 dias (Silva Sobrinho, 2001). Cada área de 0,8 ha foi subdividida em 8 piquetes de 0,1 ha, equipados com comedouro e bebedouro. A composição bromatológica do capim-tifton 85 (Cynodon dactylon) durante o período experimental foi de $14,9 \%$ de proteína bruta; $66,9 \%$ de fibra em detergente neutro; 27,7\% de fibra em detergente ácido; e 8,3\% de lignina.

Para a produção de carne de cordeiro no sistema orgânico, foram utilizados os princípios e fundamentos das diretrizes do Instituto Biodinâmico (2006), localizado em Botucatu, São Paulo, que acompanhou o desenvolvimento desta pesquisa. Também foram utilizados grãos provenientes de unidades certificadas pelo referido instituto.

Os cordeiros foram abatidos aos $32 \mathrm{~kg}$ de peso corporal, após 16 horas de jejum de sólidos. A insensibilização foi realizada por eletronarcose de $220 \mathrm{~V}$ por 8 segundos e, em seguida, foram seccionadas as veias jugulares e as artérias carótidas para a sangria, de acordo com procedimentos que caracterizam o abate humanitário (Monteiro Júnior, 2000).

Os cordeiros criados no sistema convencional foram abatidos aos 206 dias de idade e aqueles do sistema convencional aos 169 dias, todos aos $32 \mathrm{~kg}$ de peso corporal, uma vez que em sistemas orgânicos de produção são aplicadas técnicas alternativas para controle parasitário, como homeopatia e fitoterapia, que exigem mais tempo
Tabela 1 - Composição da dieta experimental fornecida às ovelhas nos sistemas de produção orgânico e convencional

\begin{tabular}{lcc}
\hline Composição percentual (\%) & \multicolumn{2}{c}{ Sistema de produção } \\
\cline { 2 - 3 } & Orgânico & Convencional \\
\hline Milho moído & 17,60 & 17,60 \\
Farelo de soja & 22,00 & 22,00 \\
Fosfato bicálcico & 0,14 & 0,14 \\
Sal mineral & 0,26 & 0,26 \\
Cana-de-açúcar & 60,00 & 60,00 \\
Composição bromatológica & & \\
Matéria seca (\% MS) & 53,38 & 54,72 \\
Matéria mineral (\% MS) & 1,80 & 1,79 \\
Proteína bruta (\% MS) & 17,26 & 17,56 \\
Extrato etéreo (\% MS) & 2,62 & 1,01 \\
Fibra em detergente neutro (\% MS) & 15,60 & 17,66 \\
Fibra em detergente ácido (\%MS) & 18,98 & 22,51 \\
Energia bruta (Mcal/kg MS) & 2,39 & 2,37 \\
\hline
\end{tabular}

Tabela 2 - Composição da ração experimental fornecida aos cordeiros lactentes nos sistemas de produção orgânico e convencional

\begin{tabular}{lcc}
\hline Composição percentual (\%) & \multicolumn{2}{c}{ Sistema de produção } \\
\cline { 2 - 3 } & Orgânico & Convencional \\
\hline Milho moído & 60,00 & 60,00 \\
Farelo de soja & 25,00 & 25,00 \\
Farelo de trigo & 11,50 & 11,50 \\
Fosfato bicálcico & 3,00 & 3,00 \\
Sal mineral & 0,50 & 0,50 \\
Composição bromatológica & & \\
Matéria seca (\% MS) & 90,32 & 90 \\
Matéria mineral (\% MS) & 5,39 & 5,45 \\
Proteína bruta (\% MS) & 19,31 & 16,61 \\
Extrato etéreo (\% MS) & 4,32 & 3,03 \\
Fibra em detergente neutro (\% MS) & 19,63 & 23,14 \\
Fibra em detergente ácido (\%MS) & 3,89 & 5,84 \\
Energia bruta (Mcal/kg MS) & 3,91 & 3,87 \\
\hline
\end{tabular}

Tabela 3 - Composição da ração experimental fornecida aos cordeiros desmamados nos sistemas de produção orgânico e convencional

\begin{tabular}{lcc}
\hline Composição percentual (\%) & \multicolumn{2}{c}{ Sistema de produção } \\
\cline { 2 - 3 } & Orgânica & Convencional \\
\hline Milho moído & 18,00 & 18,00 \\
Farelo de soja & 30,50 & 30,50 \\
Fosfato bicálcico & 1,30 & 1,30 \\
Suplemento mineral & 0,20 & 0,20 \\
Cana-de-açúcar & 50,00 & 50,00 \\
Composição bromatológica & & \\
Matéria seca (\% MS) & 59,87 & 60,99 \\
Matéria mineral (\% MS) & 3,49 & 3,46 \\
Proteína bruta (\% MS) & 14,83 & 15,78 \\
Extrato etéreo (\% MS) & 3,23 & 2,14 \\
Fibra em detergente neutro (\% MS) & 15,01 & 17,25 \\
Fibra em detergente ácido (\%MS) & 6,28 & 7,64 \\
Energia bruta (Mcal/kg MS) & 2,67 & 2,62 \\
\hline
\end{tabular}


para expressar efeito e promover o peso de abate em relação às do sistema convencional, no qual é permitida a utilização da alopatia.

Imediatamente após o abate, as carcaças foram pesadas e mantidas em câmara frigorífica a $4{ }^{\circ} \mathrm{C}$ por 24 horas. Em seguida, foram pesadas novamente e divididas longitudinalmente em duas meias-carcaças: a esquerda foi seccionada em pescoço, paleta, costelas, lombo e perna. Os cortes foram pesados para cálculo do rendimento em relação ao peso da carcaça e a área de olho-de-lombo do músculo longissimus $\left(\mathrm{cm}^{2}\right)$ foi calculada entre a $12^{\underline{a}} \mathrm{e}$ a $13^{\text {a }}$ costelas, efetuando-se mensurações em sua área transversal, medida A ou largura máxima; medida B ou profundidade máxima; medida $C$ ou espessura mínima de gordura sobre o músculo; e medida GR ou maior espessura de gordura de cobertura no perfil do lombo a $11 \mathrm{~cm}$ da linha média. Foram retiradas amostras do músculo longissimus dorsi para determinação da composição centesimal (umidade, proteína, gordura e matéria mineral), de acordo com Silva \& Queiroz (2006), e do perfil de ácidos graxos, conforme Bligh \& Dyer (1959).

O delineamento experimental foi o inteiramente casualizado, com dois tratamentos e 24 repetições. As comparações dos contrastes entre médias dos tratamentos foram feitas pelo teste de Tukey a 5\%, conforme procedimentos do SAS (1996).

\section{Resultados e Discussão}

Os sistemas de produção não influenciaram $(\mathrm{P}>0,05) \mathrm{o}$ peso e a porcentagem dos cortes da carcaça, provavelmente porque, de acordo com a lei da harmonia anatômica (Boccard citado por Siqueira, 2000), a proporção dos cortes da carcaça apresenta poucas alterações entre animais abatidos ao mesmo peso e os valores observados foram aqueles comumente encontrados para cordeiros (Tabelas 4 e 5).

Valores próximos aos obtidos neste estudo nos sistemas de produção orgânica e convencional foram relatados por Karim et al. (2007), que, estudando a composição regional da carcaça de cordeiros Kheri abatidos aos $31 \mathrm{~kg}$ criados em sistemas semiextensivos (pastagem + concentrado ad libitum), observaram valores de $24,7 \%$ para porcentagem do pescoço com a paleta, 29,4\% para costelas, $12,6 \%$ para o lombo e $33,3 \%$ para a perna.

Araújo Filho et al. (2010) avaliaram a composição da carcaça de cordeiros Dorper $\times$ Santa Inês em confinamento recebendo dieta constituída por feno de capim-tifton 85 e concentrado, observaram nos cordeiros abatidos aos $30 \mathrm{~kg}$ de peso corporal, peso do pescoço, da paleta, das costelas, do lombo e da perna de 0,$48 ; 1,19 ; 1,80 ; 1,06$ e $2,20 \mathrm{~kg}$, respectivamente, e porcentagem dos cortes da carcaca de 7,20\% para o pescoço, 17,68\% para a paleta, $26,70 \%$ para as costelas, $15,76 \%$ para o lombo e $32,66 \%$ para a perna. Os pesos e rendimentos do pescoço, da paleta e da perna obtidos neste estudo foram superiores aos obtidos por Araújo Filho et al. (2010).

O comprimento máximo do músculo longissimus dorsi dos cordeiros criados no sistema orgânico foi superior $(5,56 \mathrm{~cm})$ aos do sistema convencional $(5,15 \mathrm{~cm})$, assim como a espessura máxima de gordura de cobertura sobre o perfil do lombo, cujos valores foram de 3,21 e 2,06 mm, respectivamente (Tabela 6), sendo que, em ambos os casos, a espessura máxima de gordura de cobertura foi considerada escassa (Silva Sobrinho et al., 2008).

Tabela 4 - Peso (kg) dos cortes da carcaça de cordeiros criados nos sistemas de produção orgânico e convencional

\begin{tabular}{lccc}
\hline Componente regional $(\mathrm{kg})$ & \multicolumn{2}{c}{ Sistema de produção } & Pr>F \\
\cline { 2 - 3 } & Orgânico & Convencional & \\
\hline Pescoço & 0,58 & 0,53 & 0,3157 \\
Paleta & 1,51 & 1,35 & 0,0473 \\
Costelas & 1,76 & 1,62 & 0,2254 \\
Lombo & 0,87 & 0,79 & 0,0525 \\
Perna & 2,32 & 2,23 & 0,3134 \\
\hline
\end{tabular}

Tabela 5 - Porcentagem (\%) dos cortes da carcaça de cordeiros criados nos sistemas de produção orgânico e convencional

\begin{tabular}{|c|c|c|c|c|}
\hline \multirow[t]{2}{*}{ Componente regional (\%) } & \multicolumn{2}{|c|}{ Sistema de produção } & \multirow[t]{2}{*}{$\operatorname{Pr}>F$} & \multirow[t]{2}{*}{ CV (\%) } \\
\hline & Orgânico & Convencional & & \\
\hline Pescoço & 8,16 & 8,11 & 0,9202 & 12,77 \\
\hline Paleta & 21,44 & 20,71 & 0,4259 & 7,87 \\
\hline Costelas & 24,91 & 24,77 & 0,9018 & 8,66 \\
\hline Lombo & 12,40 & 12,09 & 0,5048 & 7,03 \\
\hline Perna & 32,94 & 34,08 & 0,2157 & 4,88 \\
\hline
\end{tabular}


A profundidade máxima do músculo $(2,90 \mathrm{~cm})$, a espessura mínima de gordura de cobertura $(1,44 \mathrm{~mm})$ e a área de olho-de-lombo $\left(12,21 \mathrm{~cm}^{2}\right)$ não diferiram $(\mathrm{P}>0,05)$ entre os tratamentos.

A área de olho-de-lombo encontrada neste experimento para os cordeiros criados nos sistemas orgânico e convencional, de $12,21 \mathrm{~cm}^{2}$, foi inferior à observada por Karim et al. (2007), que, avaliando a área de olho-de-lombo de cordeiros Kheri abatidos aos $31 \mathrm{~kg}$ criados em sistemas semiextensivos (pastagem + concentrado ad libitum), observaram valor de $14 \mathrm{~cm}^{2}$.

Estudando a composição da carcaça e a qualidade da carne de cordeiros Texel criados em sistema extensivo e abatidos entre 35 e $38 \mathrm{~kg}$, Johnson et al. (2005) observaram no músculo longissimus dorsi largura máxima, profundidade máxima, espessura mínima de gordura de cobertura e espessura máxima de gordura de cobertura sobre o perfil do lombo (11 cm da linha média) de 58,1; 26,7; 2,1 e 5,7 mm, respectivamente. As medidas $\mathrm{B}, \mathrm{C}$ e $\mathrm{D}$, no entanto, foram superiores as encontradas nesta pesquisa, possivelmente devido ao maior peso de abate e à maior deposição de gordura na carcaça. Entretanto, os autores observaram área de olho-de-lombo de $11,8 \mathrm{~cm}^{2}$ e, neste estudo, o valor obtido foi maior $\left(12,21 \mathrm{~cm}^{2}\right)$ em ambos os sistemas estudados (orgânico e convencional).

Na composição centesimal do músculo longissimus dorsi de cordeiros (Tabela 7), apenas a matéria mineral foi influenciada $(\mathrm{P}<0,05)$ e apresentou menor valor no sistema orgânico $(1,02)$ em relação ao convencional $(1,09 \%)$. Para os conteúdos de matéria seca, proteína e gordura, não houve $(P>0,05)$ influência dos sistemas de produção.

Morbidini et al. (1999) avaliaram a carne de cordeiros Merino nos sistemas orgânico e convencional e observaram também diferenças $(\mathrm{P}<0,05)$ no teor de matéria mineral no músculo longissimus dorsi, com valores de 1,25 e 1,04\% para os sistemas orgânico e convencional, respectivamente. Os teores de matéria seca, proteína bruta e gordura, no entanto, não diferiram $(\mathrm{P}>0,05)$ entre os sistemas de produção.

Estudando o efeito dos sistemas de produção orgânica e convencional sobre a composição centesimal do músculo longissimus dorsi de bezerros com idade entre 18 e 24 meses, Walshe et al. (2006) não verificaram influência ( $\mathrm{P}>0,05)$ nos teores de proteína (22,74\%) e matéria mineral $(1,14 \%)$. Entretanto, diferenças foram observadas para os teores de gordura e umidade, pois os valores encontrados no sistema orgânico foram de 3,37 e 72,86\% e, no sistema convencional, de 1,98 e 74,04\%, respectivamente.

De acordo com Prata (1999), a composição centesimal da carne ovina é de $75 \%$ de umidade, $19 \%$ de proteína, $4 \%$ de gordura, $1,1 \%$ de matéria mineral e menos que $1 \%$ de carboidratos. Nesta pesquisa, os valores observados foram próximos aos citados por esse autor, salvo o teor de gordura, que foi inferior.

A composição em ácidos graxos saturados e monoinsaturados não foi influenciada $(\mathrm{P}>0,05)$ pelos sistemas de produção, entretanto, o teor de ácido graxo poliinsaturado C18:2 (linoleico) foi maior (4,69\%) na carne

Tabela 6 - Mensurações no músculo longissimus dorsi de cordeiros criados nos sistemas de produção orgânico e convencional

\begin{tabular}{|c|c|c|c|c|}
\hline \multirow[t]{2}{*}{ Medida } & \multicolumn{2}{|c|}{ Sistema de produção } & \multirow[t]{2}{*}{$\operatorname{Pr}>F$} & \multirow[t]{2}{*}{ CV (\%) } \\
\hline & Orgânico & Convencional & & \\
\hline A $(\mathrm{cm})$ & $5,56 a$ & $5,15 b$ & 0,0318 & 5,94 \\
\hline $\mathrm{B}(\mathrm{cm})$ & 2,94 & 2,86 & 0,5726 & 8,78 \\
\hline $\mathrm{C}(\mathrm{mm})$ & 1,74 & 1,14 & 0,1032 & 43,82 \\
\hline $\mathrm{D}(\mathrm{mm})$ & $3,21 \mathrm{a}$ & $2,06 \mathrm{~b}$ & 0,0326 & 33,98 \\
\hline Área $\left(\mathrm{cm}^{2}\right)$ & 12,85 & 11,58 & 0,1035 & 11,00 \\
\hline
\end{tabular}

A = largura máxima do músculo longissimus dorsi; $\mathrm{B}$ = profundidade máxima do músculo longissimus dorsi; $\mathrm{C}=$ espessura mínima de gordura de cobertura sobre o músculo longissimus dorsi; $\mathrm{D}=$ espessura máxima de gordura de cobertura sobre o perfil do lombo $(11 \mathrm{~cm}$ da linha média $) ;$ Área = área do músculo longissimus dorsi = $(\mathrm{A} / 2 \mathrm{x} \mathrm{B} / 2) \pi$. a,b Médias seguidas por letras distintas na mesma linha diferem entre si pelo teste Tukey a 5\% de probabilidade.

Tabela 7 - Composição centesimal (\%) do músculo longissimus dorsi de cordeiros criados nos sistemas de produção orgânico e convencional

\begin{tabular}{|c|c|c|c|c|}
\hline \multirow[t]{2}{*}{ Parâmetro (\%) } & \multicolumn{2}{|c|}{ Sistema de produção } & \multirow[t]{2}{*}{$\operatorname{Pr}>F$} & \multirow[t]{2}{*}{ CV (\%) } \\
\hline & Orgânico & Convencional & & \\
\hline Umidade & 77,44 & 77,41 & 0,9563 & 1,66 \\
\hline Proteína & 18,73 & 18,93 & 0,7606 & 6,54 \\
\hline Gordura & 2,10 & 1,77 & 0,1271 & 20,30 \\
\hline Matéria mineral & $1,02 b$ & $1,09 \mathrm{a}$ & 0,0272 & 5,28 \\
\hline
\end{tabular}

a,b Médias seguidas de letras diferentes na mesma linha diferem pelo teste Tukey a 5\% de probabilidade. 
dos cordeiros provenientes do sistema orgânico em comparação aos 3,73\% observados na carne dos cordeiros criados no sistema convencional (Tabela 8). As proporções de ácidos graxos saturados (54,29\%), monoinsaturados (39,85\%) e poliinsaturados (5,87\%) nesta pesquisa seguiram a linearidade daquelas reportadas por Silva Sobrinho (2001), de 55,07; 31,37 e 5,36\% para porcentagem desses ácidos graxos no músculo longissimus dorsi de cordeiros terminados em pastagem.

Da mesma forma, Hocquette et al. (2005) observaram que, na gordura dos ruminantes, os ácidos graxos saturados variaram de 40 a $60 \%$, os monoinsaturados de 30 a $50 \%$, e que a proporção foi maior para o ácido oleico e os poliinsaturados na proporção de $5 \%$, sendo o ácido linoleico o mais abundante. Nesta pesquisa, tanto os ácidos oleico quanto o linoleico foram encontrados em maiores proporções entre os ácidos graxos mono e poliinsaturados. No sistema orgânico, as porcentagens de ácido oleicos e linoleico foram de 38,3 e 4,69\% e, no sistema convencional, 37,95 e 3,73\%, respectivamente. Oliveira et al. (2008) descreveram que o ácido linoleico tem propriedade para reduzir as lipoproteínas de baixa densidade (LDL), que são prejudiciais à saúde humana, e aumentar as lipoproteínas de alta densidade (HDL).

Em experimento para avaliar a carne de cordeiros Merino criados nos sistemas orgânico e convencional, Morbidini et al. (1999) observaram diferença $(\mathrm{P}<0,05)$ no perfil de ácidos graxos, com valores de 0,67 e 0,56\% para o C15:0;
0,007 e 0,016\% para o C23:0; 0,63 e 0,37\% para C14:1 n-6; 3,20 e 2,59\% C16:1; 0,97 e 0,82\% para C18:3 n-3; 0,34 e 0,23\% para C20:5 n-3; e 0,16 e 0,09\% para C22:6 n-3. Os resultados observados nesta pesquisa se contrapõem, no entanto, aos descritos por esses autores, uma vez que apenas o ácido linoleico foi influenciado pelos sistemas de produção.

Angood et al. (2008) estudaram a qualidade da carne de cordeiros (músculo longissimus lumborum) produzidos nos sistemas orgânico e convencional e observaram que o ácido graxo saturado esteárico (C18:0), o monoinsaturado oleico (C18:1) e o poliinsaturado linolênico (C18:3) foram influenciados $(\mathrm{P}<0,05)$ pelos sistemas de produção, com valores de 13,70 e $14,89 \%$; 1,33 e 1,13\% e 1,67 e 1,95\%, respectivamente. Na carne de novilhos, Walshe et al. (2006) observaram que o perfil de ácidos graxos no músculo longissimus dorsi nos sistemas orgânico e convencional não diferiu $(\mathrm{P}>0,05)$ entre os sistemas de produção. Para os ácidos graxos saturados C14:0 (mirístico), C16:0 (palmítico) e C18:0 (esteárico), insaturados C16:1 (palmitoleico) e C18:1 (oleico) e poliinsaturados C18:2 (linoleico) e C18:3 (linolênico), os teores médios na carne foram de 4,38; 50,11; 59,05; 5,09; 63,48; 4,60 e 2,29 mg/g de gordura, respectivamente.

Os sistemas de produção não influenciaram $(\mathrm{P}>0,05)$ a contagem de ovos por grama de fezes das ovelhas lactantes e dos cordeiros lactentes, com valores de 24.686 e 9.207 , respectivamente. Este fato ocorreu provavelmente devido

Tabela 8 - Perfil (\%) de ácidos graxos do músculo longissimus dorsi de cordeiros criados nos sistemas de produção orgânico e convencional

\begin{tabular}{|c|c|c|c|c|}
\hline \multirow[t]{2}{*}{ Parâmetro (\%) } & \multicolumn{2}{|c|}{ Sistema de produção } & \multirow[t]{2}{*}{$\operatorname{Pr}>F$} & \multirow[t]{2}{*}{ CV (\%) } \\
\hline & Orgânico & Convencional & & \\
\hline Saturados & 53,5 & 55,07 & - & - \\
\hline C10:0 (cáprico) & 0,17 & 0,17 & 0,7791 & 19,54 \\
\hline C12:0 (láurico) & 0,25 & 0,24 & 0,9451 & 38,06 \\
\hline C14:0 (mirístico) & 2,93 & 2,93 & 0,9867 & 19,48 \\
\hline C15:0 (pentadecanoico) & 0,55 & 0,55 & 0,8966 & 10,90 \\
\hline C16:0 (palmítico) & 21,23 & 21,96 & 0,3865 & 7,32 \\
\hline C17:0 (margárico) & 1,29 & 1,39 & 0,1416 & 9,08 \\
\hline C18:0 (esteárico) & 26,87 & 27,62 & 0,7590 & 16,94 \\
\hline C20:0 (araquídico) & 0,21 & 0,21 & 0,9912 & 28,84 \\
\hline Monoinsaturados & 40,15 & 39,54 & - & - \\
\hline C14:1 (meristoleico) & 0,066 & 0,068 & 0,9035 & 41,85 \\
\hline C16:1 (palmitoleico) & 1,22 & 1,26 & 0,7577 & 19,37 \\
\hline C17:1 (heptadecanoico) & 0,48 & 0,53 & 0,3384 & 20,79 \\
\hline C18:1 (oleico) & 38,30 & 37,59 & 0,6572 & 7,92 \\
\hline C20:1 (elaídico) & 0,08 & 0,09 & 0,5649 & 22,41 \\
\hline Poliinsaturados & 6,35 & 5,38 & - & - \\
\hline C18:2 (linoleico) & 4,69a & 3,73b & 0,0276 & 17,96 \\
\hline C18:3 (linolênico) & 0,67 & 0,64 & 0,6222 & 18,51 \\
\hline C20:3 (eicosatrienoico) & 0,30 & 0,36 & 0,5530 & 60,55 \\
\hline CLA (linoleico conjugado) & 0,69 & 0,65 & 0,6973 & 25,17 \\
\hline
\end{tabular}

a,b Médias seguidas de letras diferentes na mesma linha diferem pelo teste Tukey a 5\% de probabilidade. 
à imunidade fornecida pelo colostro nesta fase inicial, entretanto, os valores foram altos se comparados ao permitido, de 1.000 ovos por grama de fezes (Sloss et al., 1999). Nas ovelhas, a lactação é a fase de maior exigência nutricional e mais susceptível à ocorrência de verminoses. Cabe destacar a provável resiliência de alguns animais que apresentaram altos valores de ovos por grama de fezes associados a escores Famacha 1 ou 2, o que confere boa irrigação sanguínea na mucosa da conjuntiva ocular. Nos cordeiros do sistema de produção orgânica, os valores foram mais altos (14.914) em relação aos do sistema convencional (4.057), fato decorrente do controle dos endoparasitas no sistema orgânico, que foi realizado com homeopatia e fitoterapia, técnicas que neste estudo não foram tão eficazes quanto a alopatia.

Zeola et al. (2007) avaliaram a utilização de medicamento homeopático comercial fornecido no concentrado de ovelhas Ile de France gestantes e observaram que o fornecimento ou a ausência do produto não influenciaram $(\mathrm{P}>0,05)$ o número de ovos por grama de fezes nesta categoria animal, com valores, respectivamente, de 724 e 532, bem inferiores aos encontrados nesta pesquisa. Cabaret et al. (2003) citaram que a infecção por helmintos é usualmente maior em sistema de produção orgânica em relação ao convencional e, por esta razão, quando utilizada homeopatia, o controle parasitário do rebanho exigirá maior cuidado no manejo sanitário.

\section{Conclusões}

O peso e a porcentagem dos cortes da carcaça são semelhantes entre cordeiros produzidos nos sistemas de produção orgânica e convencional, entretanto a carne daqueles criados no sistema orgânico apresenta maior largura máxima no músculo longissimus dorsi (medida A) e porcentagem do ácido graxo poliinsaturado linoleico e menor teor de matéria mineral.

\section{Agradecimentos}

À Fundação de Amparo à Pesquisa do Estado de São Paulo (FAPESP), pelo auxílio financeiro e pela bolsa de estudos.

À Usina Santo Antônio S/A, pelo fornecimento da cana-de-açúcar produzida no sistema orgânico.

Ao Instituto Biodinâmico (IBD), pelo fornecimento das diretrizes para criação de animais domésticos no sistema orgânico de produção.

\section{Referências}

ANGOOD, K.M.; WOOD, J.D.; NUTE, G.R. A comparison of organic and conventionally-produced lamb purchased from three major UK supermarkets: Price, eating quality and fatty acid composition. Meat Science, v.78, p.176-184, 2008.

ARAÚJO FILHO, J.A. Produção orgânica de carne de ovinos e caprinos. In: SEMINÁRIO NORDESTINO DE PECUÁRIA, 6., 2002, Fortaleza. Anais... Fortaleza: PEC Nordeste, 2002. p.111-112.

ARAÚJO FILHO, J.T.; COSTA, R.G.; FRAGA, A.B. et al. Desempenho e composição da carcaça de cordeiros deslanados terminados em confinamento com diferentes dietas. Revista Brasileira de Zootecnia, v.39, n.2, p.363-371, 2010.

BELLAVER, C. Produção animal e qualidade de vida nas sociedades em transição. In: REUNIÃO ANUAL DA SOCIEDADE BRASILEIRA DE ZOOTECNIA, 39., 2002, Recife. Anais... Recife: Sociedade Brasileira de Zootecnia, 2002. p.317-331.

BARBOSA FILHO, J.A.D.; SILVA, J.O. Abate humanitário: ponto fundamental do bem-estar animal. Revista Nacional da Carne, n.328, p.36-44, 2004.

BLIGH, E.G.; DYER, W.J. A rapid method of total lipid extraction and purification. Canadian Journal of Biochemistry and Physiology, v.37, n.8, p.911-917, 1959.

CABARET, J. Animal health problems in organic farming: subjective and objective assessments and farmers' actions. Livestock Production Science, v.80, p.99-108, 2003.

D'ALMEIDA, T.N. Bem-estar animal x segurança alimentar. Higiene Alimentar, v.19, n.132, p.15-17, 2005.

GALVÃO, F. Rebanho lucrativo. Isto é Dinheiro, n.350, p.82-83, 2004.

HOCQUETTE, J.F.; RICHARDSON, R.I.; PRACHE, S. et al. The future for research on quality and safety of animal products. Italian Journal of Animal Science, v.4, n.3, p.49-72, 2005.

INSTITUTO BIODINÂMICO - IBD. Diretrizes para o padrão de qualidade “Orgânico Instituto Biodinâmico”. 13.ed. Botucatu, 2006. 87p.

INSTITUTO ADOLFO LUTZ. Normas analíticas do Instituto Adolfo Lutz. métodos físico-químicos para análise de alimentos. 4.ed. São Paulo: IMESP, 2008. 1020p.

JOHNSON, P.L.; PURCHAS, R.W.; McEWAN, J.C. et al. Carcass composition and meat quality differences between pasture-reared ewe and ram lambs. Meat Science, v.71, p.383-391, 2005.

KARIM, S.A.; PORWAL, K.; KUMAR, S. et al. Carcass traits of Kheri lambs maintained on different system of feeding management. Meat Science, v.76, p.395-401, 2007.

MOLENTO, M.B.; TASCA, C.; GALLO, A. et al. Método Famacha como parâmetro clínico individual de infecção por haemonchus contortus em pequenos ruminantes. Ciência Rural, v.34, n.4, 2004.

MONTEIRO JÚNIOR, L.A. Avaliação das técnicas de insensibilização de ovinos abatidos na região de Botucatu. 2000. 166f. Dissertação (Mestrado em Medicina Veterinária) Faculdade de Medicina Veterinária e Zootecnia/Universidade Estadual Paulista, Botucatu.

MORBIDINI, L.; SARTI, D.M.; POLIDORI, P. et al. Carcass, meat and fat quality in italian Merino derived lambs obtained with organic farming systems. In: RECENT PROGRESS IN ANIMAL PRODUCTION SCIENCE, 1., 1999, Piacenza. Anais...Piacenza: ASPA, 1999. p.598-600.

NARDONE, A.; ZERVAS, G.; RONCHI, B. Sustainability of small ruminant organic systems of production. Livestock Production Science, v.90, p.27-39, 2004.

NATIONAL RESEARCH COUNCIL - NRC. Nutrient requirements of small ruminants. Washington, D.C.: National Academy Press, 2006. 362p.

OLIVEIRA, R.L.; LADEIRA, M.M.; BARBOSA, M.A.A.F. et al. Ácido linoléico conjugado e perfil de ácidos graxos no músculo e na capa de gordura de novilhos bubalinos alimentados com 
diferentes fontes de lipídios. Arquivo Brasileiro de Medicina Veterinária e Zootecnia, v.60, n.1, 2008.

PAIXÃO, R.L. É possível garantir bem-estar aos animais de produção? Revista Conselho Federal de Medicina Veterinária, v.11, n.36, p.66-73, 2005.

PRATA, L.F. Higiene e inspeção de carnes, pescado e derivados. Jaboticabal:FUNEP, 1999. 217p.

SAS. User's guide: stat, version, 6.12. 4.ed. Cary: SAS Institute, 1996. v.1/2.

SANTOS, G.C.; MONTEIRO, M. Sistema orgânico de produção de alimentos. Alimentos e Nutrição, v.15, n.1, p.73-86, 2004.

SILVA, D.J.; QUEIROZ, A.C. Análise de alimentos: métodos químicos e biológicos. 3.ed. Viçosa, MG: Imprensa Universitária, 2006. 235p.

SILVA SOBRINHO, A.G. Produção de cordeiros em pastagem. In: SIMPÓSIO MINEIRO DE OVINOCULTURA, 1., 2001, Lavras. Anais... Lavras: UFLA, 2001. p.63-97.

SILVA SOBRINHO, A.G.; SAÑUDO, C.; OSÓRIO, J.C.S. et al, Produção de carne ovina. Jaboticabal: Funep, 2008. 228p.
SIQUEIRA, E.R. Sistemas de confinamento de ovinos para corte do Sudeste do Brasil. In: SIMPÓSIO INTERNACIONAL SOBRE CAPRINOS E OVINOS DE CORTE, 1., 2000, João Pessoa. Anais... João Pessoa, 2000. p.107-117.

SLOSS, M.W.; ZAJAC, A.M.; KEMP, R.L. Parasitologia clínica veterinária. São Paulo: Manole, 1999. 198p.

WALSHE, B.E.; SHEEHAN, E.M.; DELAHUNTY, C.M. et al. Composition, sensory and shelf life stability analyses of Longissimus dorsi muscle from steers reared under organic and conventional production systems. Meat Science, v.73, n.2, p.319-325, 2006.

WARRISS, P.D. Meat science: an introductory text. Wallingford: CABI Publishing, 2000. 310p.

ZEOLA, N.M.B.L.; SILVA SOBRINHO, A.G.; LEÃO, A.G. Homeopatia no controle de helmintos gastrintestinais de ovelhas em gestação. In: REUNIÃO ANUAL DA SOCIEDADE BRASILEIRA DE ZOOTECNIA, 44., 2007, Jaboticabal. Anais... Jaboticabal: Sociedade Brasileira de Zootecnia, 2007. (CD-ROM). 